\title{
Empirical Study on the Impact of Policy Events on Stock Market before and after Stock Market Disaster
}

\author{
Hui Zhang ${ }^{1,{ }^{*}}$, Chao Sun ${ }^{2}$ and Wenyu Meng ${ }^{3}$ \\ ${ }^{1,2}$ School of Mathematics and Quantitative Economics, Shandong University of Finance and \\ Economics, Jinan 250014, PR China, a \\ ${ }^{3}$ School of Finance, Shandong University of Finance and Economics, Jinan 250014, PR China \\ *Corresponding author
}

Keywords: Volatility point identification, Event methodology, Policy event return volatility.

\begin{abstract}
This paper studied the relationship between policies and stock market volatility. This paper used the volatility point discrimination method to identify the variance increase points of stock market volatility from 2014 to 2018. It finds out the policy events causing stock market fluctuations through the event research method. After regression analysis of index return and policy event return, index return volatility and policy return volatility, it is found that the impact of policy events before the shock of stock market is greater than that after the shock of stock market.
\end{abstract}

\section{Introduction}

The stock market has always been regarded as the "barometer" of national economic growth, and the fluctuations of the stock market are the core issues concerned by policy makers and stock investment. The promulgation of policies can affect the fluctuations of the market, and then promote the formulation of policies. Hu Jinyan (2002) [1] found that abnormal volatility of the stock market are related to the introduction of policies. Zou Haoping et al.(2000)[2] found that policy factors were the main causes of abnormal fluctuation of stock index. Xu Junhua et al.(2001) [3]divided macro policies into continuous policies and discrete policies when studying the impact of macro policies on the stock market. They concluded that that the effects of continuous policies on stock market are positively correlated, but the explanation degrees are low.

For the discrete policy, It is found that the stock market operation in China is greatly affected by short-term discrete policy events, but its impact is gradually weakened with the maturity of the market regulation means.

Moreover, the impact of policy is different in time and degree. As shown by the research results of Antulio N et al. (2003)[4], the stock market tends to be relatively calm in the days before the regular policy announcements. The empirical analysis of Ning jing (2010)[5] showed that the policy effect of stock market gradually declines over time, because investors tend to be rational and the government's control measures gradually mature. Wang mingtao et al. (2012)[6] found that policy events have a great influence in a bull market.

In China, stock market experienced drastic fluctuations in 2015, which have brought great shocks to investors and financial syetem. Jin yuying et al. (2016) [7]found the expansionary monetary policy before the stock market crash was not conducive to the recovery of the market after the shock of stock market, while the expansionary monetary policy after the market crash was conducive to the recovery of the stock market. Zhang xiaoqin (2017) [8]studied the Short-term effects caused by the central bank's interest rate cutsand found that the interest rate cut policy had a positive impact on the stock market. Qi Yue et al.(2018) [9]constructed the ICSS-GARCH model to analyze the event factors affecting the volatility of the market, and found that macroeconomic policies and other factors became the main reasons affecting the volatility of the Chinese stock market.

In a word, the existing literature has not made in-depth research on the influence of policy events on stock market before and after stock market disaster. So, this paper selects the Shanghai composite index from 2014 to 2018 to study the relationship between the policies issued during this 
period and market volatility, and then takes the 2015 stock market crash as a cut-off point to further study the influence of policies before and after the shock of market on stock market volatility.

\section{Empirical Analysis}

\section{The Way of Identifying Major Policy Events}

We take the daily closing price of Shanghai Composite Index as a sample, we set $P_{t}$ as the closing price of the Shanghai Composite Index on day $t$ and $P_{t-1}$ as the closing price of the Shanghai Composite Index on day $\mathrm{t}-1$. We record the rate of return on day t as follows:

$$
R_{t}=\ln \left(P_{t}\right)-\ln \left(P_{t-1}\right)
$$

We assume that the daily index log returns are independent and normally distributed with a mean of 0 . We also regrad $\mathrm{N}$ as the total of stock samples. We construct two subsamples of size $n$ from the total stock samples on date $\mathrm{t}$, where there are $\left(R_{i-n}, R_{i-n+1}, \cdots, R_{i-1}\right)$ and $\left(R_{i+1}, R_{i+2}, \cdots, R_{i+n}\right)$. Volatility is defined as the variance of two subsamples, as shown below:

$$
Q_{i-}=\sum_{i-n}^{i-1} R_{i}^{2}, Q_{i+}=\sum_{i+1}^{i+n} R_{i}^{2}
$$

$Q_{i-}$ is the initial fluctuation of day $i$ and $Q_{i+}$ is the late fluctuation of day $i$.

Constructive statistics $V_{i}$

$$
V_{i}=\frac{Q_{i+}}{Q_{i-}}
$$

The statistics obey the $\mathrm{F}$ distribution with degree of freedom $(n, n)$, satisfying the following conditions:

$$
P\left\{F_{1-\frac{\alpha}{2}}(n, n)<V_{i}<F_{\frac{\alpha}{2}}(n, n)\right\}=1-\alpha
$$

If $V_{i}>F_{\frac{\alpha}{2}}(n, n)$, it is the point of increasing variance. If $V_{i}<F_{1-\frac{\alpha}{2}}(n, n)$, it's the point of variance reduction.

\section{The Market's Response to Policy Events}

After determining the stock market policy events, we use the event study method to analyze the Index returns and their fluctuations when the stock market policy events occur. This paper assumes that the policy day is $t$, and takes a total of $2 m+1$ days of each $m$ day before and after the policy day as the time window. The first $\mathrm{m}$ day is the pre-event period, and the second $\mathrm{m}$ day is the post-event period. Here $m=5$ is chosen.

If policy i happens in time window, the return of daily average can be expressed as:

$$
\begin{aligned}
& A R_{i}=\sum_{i t-m}^{i t+m} R_{i} /(2 m+1) \\
& A Q_{i}=\sum_{i t-m}^{i t+m} R_{i}^{2} /(2 m+1)
\end{aligned}
$$

If $\mathrm{K}$ events occur in a period of time, we can use them to express events' average return and average return's fluctuation in this period:

$$
\begin{aligned}
& A A R_{T}=\sum_{i=1}^{K} A R_{i} / K \\
& A A Q_{T}=\sum_{i=1}^{K} A Q_{i} / K
\end{aligned}
$$


We suppose there are $\mathrm{J}$ trading days in a period T. The average return and it's fluctuation can be expressed as follows:

$$
\begin{aligned}
& A R_{T}=\sum_{i=1}^{J} R_{i} / J \\
& A Q_{T}=\sum_{i=1}^{J} R_{i}^{2} / J
\end{aligned}
$$

Finally, by using the statistical model, we estimate the response coefficients of return and return volatility caused by Shanghai Stock Index events, and find that policy events and volatility are related. So, we build two models to research the degree of stock index's response to policy events and volatility.

$$
\begin{aligned}
& A A R_{T}=a A R_{T}+b \\
& A A Q_{T}=c A Q_{T}+d
\end{aligned}
$$

The $A A R_{T}$ and $A R_{T}$ in the equation denote the average return of events and the average Index return. The letter $a$ denotes the response coefficient of market returns to the policy events' return, and $b$ is the error term. The $A A Q_{T}$ and $A Q_{T}$ in the formula represent the average events' return volatility and the average Index return volatility respectively. The letter $c$ denotes the response coefficient of return volatility to the policy events' return volatility, and $d$ is the error term.

We use STATA to make regression (OLS) and obtain the reaction coefficient and t value, as shown in tables 1 and 2.

Table 1. Regression results of policy events' return and Composite Index return

\begin{tabular}{|c|c|c|c|}
\hline Profit & time & $a$ & $t$ \\
\hline \multirow{3}{*}{ Policy events } & $2014.1-2018.12$ & 1.288234 & 3.39 \\
\cline { 2 - 4 } & $2014.1-2015.12$ & 1.807753 & 3.11 \\
\cline { 2 - 4 } & $2016.1-2018.12$ & 0.4876096 & 1.00 \\
\hline
\end{tabular}

The response coefficient $a$ expresses the influence of the average policy events' return. The larger the coefficient $a$ is, the greater the market reaction. From 2014 to 2015, the response coefficient is 1.80773, t value is larger and more significant. While from 2016 to 2018, the response coefficient is $0.4876096, \mathrm{t}$ value is smaller and not significant. The reason for this phenomenon may be that the market had a high sensitivity to policy, and the stock market returns fluctuated as soon as the policy came out before the stock market disaster. After the stock market crash, the influence of policy on the stock market is not significant. In addition, people lack confidence after shock of market, resulting in the impact of the average policy events return on the average index return is not significant.

Table 2. Regression results of policy events’ return volatility and Composite Index’s return volatility

\begin{tabular}{|c|c|c|c|}
\hline Volatility & time & $a$ & $t$ \\
\hline \multirow{3}{*}{ Policy events } & $2014.1-2018.12$ & 1.721955 & 13.94 \\
\cline { 2 - 4 } & $2014.1-2015.12$ & 1.963694 & 10.51 \\
\cline { 2 - 4 } & $2016.1-2018.12$ & 1.09778 & 11.28 \\
\hline
\end{tabular}

The return volatility response coefficient $c$ expresses the influence of policy event on market volatility. The larger the coefficient $c$ is, the greater the market volatility caused by the event is. From 2014 to 2015, the volatility response coefficient is 1.963694, and from 2016 to 2018, the volatility response coefficient is 1.09778 . It can be seen that the response coefficient has a downward trend. Before the stock market disaster in 2015, the fluctuation caused by policy events was more obvious, but after the stock market disaster, the fluctuation caused by policy was not significant. 


\section{Conclusions}

Through above empirical analysis, we can draw the following conclusions:

(1)Policy events have a certain influence on the earnings and volatility in China's stock market. Analyzing 2015 index earnings and policy events' earnings, index earnings volatility and policy events' earnings volatility, we get that policy events' volatility is more significant. The government should make various policies carefully, and reduce the influence of policies on the stock market. The investors should also focus on the release of policies in order to guide their own investments.

(2)The impact degree of policy events before and after the shock of market is different. Before the shock of market, the stock market was more sensitive to policy events, and investors were more inclined to give positive news for the policy events, so the policy events had a more obvious impact on the stock market. After the stock market crash, investors lacked confidence in the market. Due to the poor external economic environment, even if the introduction of good policy, investors are cautious.

\section{Acknowledgements}

This research was supported by Chinese National Natural Science Foundation (no. 11671229; no. 71803097), Natural Science Foundation of Shandong Province (no. ZR2016GB05), Shandong Provincial Education Department Humanities and Social Sciences Project (J17RB077).

\section{Reference}

[1] Hu Jinyan. Empirical Analysis of Policy Effect, Policy Efficiency and Policy City [J]. Economic Theory and Economic Management, 2002 (08): 49-53.

[2] Zou Haoping, Tang Limin, Yuan Guoliang. The Impact of Policy Factors on Chinese Stock Market: Game Analysis between Government and Stock Market Investors [J]. World Economy, 2000 (11): 20-28

[3] Xu Junhua, Li Qiya. Empirical Study on the Impact of Macro-Policy on China's Stock Market [J].Economic Research, 2001 (09): 12-21.

[4] Antulio N. Bomfim. Pre-announcement effects, news, and volatility: monetary policy and the stock market[J].Finance and Economics Discussion Series, 2000.

[5] Ningjing. Study on the Relation between Price Fluctuation and Policy Events in Chinese Stock Market [D]. Northwest University, 2010.

[6] Wang Mingtao, Lu Lei, Song Kai. The effect of policy factors on the asymmetry of stock market volatility [J]. Journal of Management Science, 2012, 15 (12): 40-57.

[7] Jin Yuying, Luo Mingjin. The impact of policy choice on stock market recovery after financial crisis: based on survival analysis method [J]. Finance and trade research, 2016, 27 (02): 18-28.

[8] Zhang Xiaoqin. A Study on the Short-term Impact of the Central Bank's Interest Rate Reduction Policy in the Period of Stock Market Turbulence Based on the Event Study Method [J].Times Finance, 2017 (26): 189-191

[9] Qi Yue, Liao Kezhi. The Impact of Policy Factors and Financial Crisis on China's Stock Market Volatility: An Analysis Based on ICSS-GARCH Model [J]. Systems Engineering, 2018, 36 (04): $12-20$ 